\title{
Antioxidant Therapy in Parkinson's Disease
}

\author{
J. David Grimes, Mohamed N. Hassan and Jay Thakar
}

\begin{abstract}
It is postulated that endogenous oxidative mechanisms are a major factor in the continuing death of dopaminergic neurons and the progression of Parkinson's disease. Scientific evidence in support of, and negating, the free radical auto-toxicity and dopamine toxicity concepts is reviewed. There is conflicting evidence whether free radicals are involved in the toxicity of 1-methyl-4-phenyl-1,2,3,6-tetrahydropyridine (MPTP) and attempts to prevent the toxicity of MPTP with antioxidant therapy have had variable results. The oxidation of dopamine by monoamine oxidase produces toxic metabolites however animal studies with high dose longterm levodopa and MPTP have failed to show clear evidence for autoxidation. Firm supportive evidence is obtained from the monoamine oxidase B inhibitor experience which demonstrated a block of the toxicity of MPTP in animals and probable prolongation of the course of human Parkinson's disease.

The scientific data available is inconclusive but there is significant hope of retarding progressive catecholaminergic neuron degenerative changes by augmenting the free radical scavenging system with antioxidants (such as Vitamin E) and slowing catecholamine oxidation by monoamine oxidase B inhibition. Careful clinical trials with these agents must be performed.
\end{abstract}

RÉSUMÉ: La thérapie par les anti-oxidants dans la maladie de Parkinson. On a postulé que les mécanismes oxidatifs endogènes sont un facteur important dans la perte graduelle de neurones dopaminergiques et dans la progression de la maladie de Parkinson. Nous revoyons les données scientifiques pour et contre les concepts d'auto-toxicité des radicaux libres et de la toxicité de la dopamine. Les observations sont contradictoires en ce qui a trait à l'implication des radicaux libres dans la toxicité du 1-méthyl-4-phényl-1,2,3,6-tétrahydropyridine (MPTP) et les tentatives de prévention de la toxicité du MPTP par les anti-oxidants ont eu des résultats variables. L'oxidation de la dopamine par la monoamine oxidase produit des métabolites toxiques; cependant, des études chez l'animal traité à long terme avec des doses élevées de lévodopa et de MPTP n'ont pas montré de façon probante qu'il y a effectivement auto-oxidation. L'utilisation expérimentale d'un inhibiteur de la mono-oxidase B, qui met en évidence un blocage de la toxicité du MPTP chez les animaux et qui prolonge probablement la durée d'évolution de la maladie de Parkinson, supporte cette théorie.

Les observations scientifiques que nous possédons actuellement ne nous permettent pas de trancher la question. Cependant, nous croyons qu'il y a bon espoir d'arriver à retarder la progression de la dégénérescence des neurones catécholaminergiques en augmentant le système de vidange des radicaux libres par l'utilisation des anti-oxidants (tel la vitamine E) et en ralentissant l'oxidation des catécholamines par l'inhibition de la monoamine oxidase B. On doit donc procéder à des essais cliniques minutieux avec ces substances.

Can. J. Neurol. Sci. 1987; 14:483-487

Endogenous oxidative mechanisms may contribute to death of dopaminergic neurons and the development and progression of Parkinson's disease. The focus for clinical pharmacology research in parkinsonism is changing to include preventive therapy. The limitations of levodopa therapy are well known' and an even greater concern is that the drug, or its metabolites, may enhance cell dysfunction. ${ }^{2}$ The selective neurotoxin I-methyl-4-phenyl-1,2,3,6 tetrahydropyridine (MPTP) has generated an explosion of new knowledge about dopaminergic neurons and their normal and abnormal biochemistry. 3,4,5,6 This new focus on exogenous toxins has also rekindled interest in, and made past information more relevant, regarding endogenous cell autotoxicity. ${ }^{7,8}$
The increased dopamine synthesis demanded of surviving nigral neurons in the parkinsonian brain produces oxy-radicals such as superoxide which may overwhelm the protective scavenging capacity of the cell and attack cell membranes through peroxidation of polyunsaturated fatty acids. ${ }^{8}$ It has been shown that free radical protective enzymes are reduced in Parkinson's disease. ${ }^{9,10}$ The free radical autotoxicity concept is supported by a number of other scientific observations.

Manganese, 6-hydroxydopamine and MPTP may all cause neuronal damage via free radical producing mechanisms. ${ }^{11.12}$ Cigarette smoking produces protective oxidative reducing agents. ${ }^{8,13}$ Deficiency of Vitamin $E$ causes intraneuronal lipofuscin deposition and increased lipid peroxides in ani- 
mals ${ }^{14.15 .16}$ and it and other antioxidants such as ascorbic acid, beta carotene and $\mathrm{N}$-acetylcysteine have had varying protective effects on MPTP induced striatal dopamine and glutathione loss. ${ }^{17.18}$ Monoamine oxidase inhibitors (MAO B type), are shown to protect animals against MPTP toxicity. ${ }^{19}$

The oxidation of dopamine by monamine oxidase also produces toxic metabolites. ${ }^{11.12 .20 .21}$ The aged brain has increased dopamine turnover ${ }^{7}$ and increased monoamine oxidase activity ${ }^{22}$ and it has been shown that L-deprenyl (a selective MAO B inhibitor) may retard the course of human Parkinson's disease and allow a reduction in levodopa dosage. ${ }^{23}$

This scientific evidence, which at present is inconclusive, raises exciting hope of retarding these catecholaminergic neuron degenerative processes in patients who either are at risk for parkinsonism or who have early disease. Augmenting the free radical scavenging system with antioxidants (such as alpha tocopherol) and inhibiting catecholamine oxidation with deprenyl are two therapeutic approaches that are now undergoing clinical evaluation.

\section{Scientific Data in Support of the Autotoxicitry Concept}

\section{Endogenous Toxins}

The evidence to support the autotoxicity, oxy-radical concept has slowly accumulated over the past 20 years. Barbeau and Calne have helped summarize and focus this information into interesting working hypotheses with treatment implications for Parkinson patients. ${ }^{7.8 .24}$ It is generally accepted that catecholamine metabolism in dopaminergic neurons produces free radicals. A free radical is defined as an atom or group of atoms with an unpaired electron occupying an outer orbit. They exist for fractions of a millisecond and are difficult to study. Free radicals are produced as oxygen is utilized and are generally present in low concentrations. They will however damage a cell if their concentration exceeds the protective scavenging capacity of the cell. It is being suggested that death of dopaminergic neurons in the substantia nigra and locus ceruleus results in reduced dopamine in the striatum and that feedback mechanisms will demand increased dopamine synthesis and turnover in remaining brainstem neurons with enhancement of free radical production. The basic concept then becomes one of a selfsustaining and progressive degenerative process of the catecholaminergic system as a result of exposure to free radicals over many years.

The most important radical is superoxide and it and hydrogen peroxide attack the polyunsaturated fatty acids in cell membranes to form lipid hydroperoxides which react with other membrane lipids to initiate a chain reaction of lipid peroxidation. ${ }^{25}$

There are cellular defenses which limit free radical damage. Superoxide dismutase scavenges superoxide radicals and catalase and glutathione peroxidase reduce hydrogen peroxide's damaging effects. In addition, reactive soluble reducing substances such as alpha tocopherol, ascorbic acid, beta carotene and uric acid attempt to maintain a balance between free radical production and consumption..$^{26}$ It has been shown that the concentrations of the protective enzymes, superoxide dismutase, catalase and glutathione peroxidase are reduced in the substantia nigra of parkinsonian patients. ${ }^{9.10}$ Other environmental factors which may contribute to the free radical excess include; nonsmoking, low consumption of reducing agents, and exposure to metal ions. Graham" "has suggested that manganese neurotoxicity and Parkinson's disease have a common pathogenesis that includes progressive neuronal injury from the oxidation products of dopamine. It has been shown that 6-hydroxydopamine also causes cell damage by the release of free radicals. ${ }^{27}$

Poirier ${ }^{28}$ has shown that other trace metals, particularly iron, which are in high concentration in the substantia nigra, enhance dopamine autoxidation and the toxicity of MPTP. Magnetic resonance imaging (MRI) has confirmed the increased basal ganglia iron content in living subjects. ${ }^{29}$

There is conflicting evidence that free radicals are involved in the toxicity of MPTP. Cells containing neuromelanin (which exists as a redox-polymer) are especially sensitive to MPTP's neurotoxic effect. Its potent metabolite MPP + resembles paraquat which induces toxicity by the generation of a superoxide radical. ${ }^{12}$ Studies have however shown that MPTP is a very poor generator of oxygen radicals and causes very little lipid peroxidation in subcellular fractions. ${ }^{30}$ Some workers have shown that antioxidants such as ascorbic acid, alpha tocopherol, beta carotene and $\mathrm{N}$-acetylcysteine protect dopaminergic neurons from MPTP toxicity. ${ }^{17.31 .32 .33}$ Others have shown that the same antioxidants fail to inhibit depletion of striatal dopamine by MPTP. ${ }^{18}$

Dopamine itself may be neurotoxic $; 2$ it undergoes spontaneous autoxidation to produce the toxic triad of reduced oxygen, hydrogen peroxide and hydroxyl radicals plus a quinone. Dopamine is normally metabolized to homovanillic acid. The presence of reactive, partially reduced oxygen molecules promotes the oxidation of catecholamines to quinones. It was suspected that MPTP may induce toxic quinone production from dopamine however animal studies have not supported the dopamine autotoxicity theory. ${ }^{34}$ The concern that dopamine itself has neurotoxic properties ${ }^{20}$ has raised suspicion that exogenous levodopa may hasten the progression of Parkinson's disease. ${ }^{2}$ These clinical concerns have not been supported by pathological studies of animals treated with longterm high dose levodopa. ${ }^{35,36}$ Quinn has recently reported preservation of the substantia nigra in a patient without Parkinson's disease who was treated for four years with levodopa ${ }^{37}$ It has also been suggested that some endogenous dopamine may be converted to the neurotoxin 6-hydroxydopamine and this may be part of amphetamine toxicity. ${ }^{38}$

\section{Neuromelanin}

The study of neuromelanin adds a further interesting dimension to the auto-toxicity discussion as its accumulation may promote cellular dysfunction and degeneration. ${ }^{12}$ Brain areas with more neuromelanin are more sensitive to the cytotoxic effect of MPTP. ${ }^{39}$ However there are pigmented brainstem nuclei that are not damaged by MPTP. ${ }^{34}$ Neuromelanin was initially thought to be a slowly accumulating waste product of catecholamine metabolism. Neuromelanin contains quinones and hydroxyquinones and is formed by the autoxidation and polymerization of tyrosine and dopamine and its accumulation is enhanced by deficient cellular defense mechanisms. Insufficient reserves of antioxidants (including Vitamin E) result in increased collection of lipopigments ${ }^{40}$ and Bannon has suggested that MPTP may decrease glutathione in the substantia nigra and results in more dopaquinone formation and subsequent conversion to melanin. ${ }^{41}$ 


\section{Smoking}

Epidemologic studies have suggested a protective effect of cigarette smoking on the risk of Parkinson's disease ${ }^{13}$ Smoking facilitates dopamine release and dopaminergic neural transmission throughout the nervous system and in this way might reduce the clinical expression of parkinsonism. A more relevant consideration is that of Calne and Langston ${ }^{8}$ that smoking results in an increase in protective reducing agents such as carbon monoxide and this increase in reduction potential traps free radicals and protects against oxidative mediated neuronal damage. It has also been suggested that smoking may induce protective enzyme systems (cytochrome $\mathrm{P} 450$ ) in the liver that would enhance the elimination of toxic compounds.

\section{Environmental and Aging Factors}

The time to initiate parkinsonism protective therapy has interesting considerations. Hornykiewicz ${ }^{42}$ noted that mild, clinically just detectable symptoms of parkinsonism are associated with more than 80 per cent loss of striatal dopamine. It is also accepted that the number of neurons in the substantia nigra decreases with age and is most pronounced in patients with Parkinson's disease. ${ }^{43}$ If endogenous or environmental factors are important in this slow degenerative process then consideration must be given to early rather than later life so that preventive therapy could be more effective. ${ }^{44}$ The practical implementation of early life therapy to retard dopamine neuronal cell dysfunction is obviously not possible at present but interesting theories regarding rural environment and well water use have been proposed. ${ }^{45}$ Increased age has been shown to be an important factor in increasing the susceptibility of animals to the toxic effects of MPTP ${ }^{46}$ and pathological changes more suggestive of Lewy bodies have now been seen in older MPTP treated monkeys. $^{47}$

The possibility that idiopathic Parkinson's disease may be caused by repeated exposure to one or more endogenous or exogenous MPTP-like compounds has produced a number of interesting theories. Ramsden, ${ }^{48}$ Fellman $^{49}$ and Testa ${ }^{50}$ have commented on the possible production of toxic endogenous methylpyridium compounds from tryptamine and catecholamines and Barbeau ${ }^{51}$ has suggested that Parkinson patients have an inherent susceptibility to environmental toxins. The search for exogenous neurotoxins continues with interesting findings such as that of the food neurotoxin (false sago palm seed) in motor neuron disease of Guam. ${ }^{52}$

\section{Vitamin E}

Vitamin $\mathrm{E}$ acts as a lipid soluble antioxidant in the nervous system; it inhibits the oxidation of unsaturated fatty acids. It is stated that the antioxidant effect of tocopherols is their major biological activity. ${ }^{53}$ Vitamin $E$ contains a 6-hydroxychroman ring which reacts with free radicals and a 16 carbon hydrophobic side chain which promotes lipid solubility. Eight compounds have been isolated with Vitamin E reactivity and alpha tocopherol has the greatest antioxidant potency as a free radical scavenger. ${ }^{54}$ Vitamin E appears to be located in cell membranes close to enzymes that produce free radicals. ${ }^{55.56}$ No clinical evidence of parkinsonism or basal ganglia pathological changes have been documented in human Vitamin E deficiency. Clinically significant Vitamin $\mathrm{E}$ deficiency is only seen in fat malabsorption disorders and then manifests with retinal, sensorimotor and cerebellar defects which are halted with replacement therapy. ${ }^{57.58 .59}$ In animals, Vitamin E deficiency causes intraneuronal lipofuscin accumulation ${ }^{14.15}$ and this can be avoided by treatment with alpha tocopherol, selenium and reduced glutathione. ${ }^{40}$ There are also age related increases in lipid peroxide formation which may be reversed with Vitamin $E .^{16}$

\section{MonoAmine OXIDASE INHIBITION}

There is considerable evidence to support the proposal that inhibition of brain monoamine oxidase (MAO) will slow the progression of dopaminergic cell dysfunction. The oxidation of dopamine by $\mathrm{MAO}$ can produce toxic metabolites including 6-hydroxy dopamine, quinones, and hydrogen peroxide. ${ }^{11.201 .21 .27}$ The aged brain has an increase in monoamine oxidase activity and this becomes significant when one considers the requirements for increased dopamine from this reduced number of nigral neurons. ${ }^{22}$ Clinical studies have demonstrated that L-deprenyl, a selective MAO B blocker may prolong the course of human Parkinson's disease and reduce the requirement for levodopa. ${ }^{23}$ The brain contains predominately monamine oxidase $B$ and one autopsy study has confirmed that there is almost complete inhibition of MAO B in patients treated with deprenyl and levodopa. ${ }^{60}$ MPTP induces parkinsonism in many animal species and this is prevented by pre-treatment with monoamine oxidase $B$ inhibitors. ${ }^{61}$

\section{Clinical Considerations}

It is important that large, carefully documented clinical trials be completed to evaluate the antioxidant, auto-toxicity concept. The success of such trials will be completely dependent on well defined clinical parameters. The best model is likely to select patients with early Parkinson's disease, treat them with antioxidant therapy, and document that the rate of disease progression and requirement for levodopa therapy are both delayed as compared to previous experience. Spinal fluid homovanillic acid levels may be followed as a measure of dopamine metabolism but there are no studies now available to monitor free radical activity and lipid peroxidation changes.

Vitamin $\mathrm{E}$ is an excellent choice as an antioxidant. It is more potent than ascorbate or beta carotene. ${ }^{62}$ The doses used in malabsorption states average $100 \mathrm{mg}$ per kilogram per day and the recommended daily dietary allowance is $10-30 \mathrm{mg}$ per day. ${ }^{53}$ Therefore doses of one to three grams daily should be more than sufficient as antioxidant therapy. No human trial has yet been published using Vitamin E as Parkinson preventive therapy.

Experience world-wide with Deprenyl indicates that it is a safe drug, which at low dosage is free of the "cheese" effect, and that a dose of $10 \mathrm{mg}$ daily inhibits $95 \%$ of MAO B activity. ${ }^{63}$ Some concerns have however surfaced; Yahr ${ }^{64}$ found a number of adverse effects including gastric bleeding and the drug is metabolized to methamphetamine which raises potential toxicological considerations.

\section{Discussion}

The above scientific data raises both positive and negative points relating to the use of antioxidant therapy for the prevention of progression of Parkinson's disease. 
The positive points in favour of this theory will be reviewed first. The excess oxy-radical auto-toxicity concept while not conclusive has a reasonable scientific basis. The fact that free radical protective enzymes are reduced in the brain of Parkinson patients and the support for the free radical theory gained from the manganese and 6-hydroxydopamine stories is of note. Cigarette smoking may increase reducing agents and have a protective effect. Vitamin $\mathrm{E}$ is a known antioxidant and free radical scavenger. A deficiency of Vitamin E causes intra neuronal lipofuscin accumulation which may promote neuronal dysfunction. Firm evidence for the endogenous oxidative damage theory is derived from the monoamine oxidase data. Monoamine oxidase is increased in the older brain. Monoamine oxidase B inhibitors block the toxicity of MPTP, and deprenyl may prolong the course of human Parkinson's disease.

A number of points that are not supportive of the antioxidant therapy concept come out of this review. It is by no means definitely clear that the free radical auto-toxicity concept is a factor in the progression of parkinsonism or aging of cells in general.

The variable protective effects of antioxidants against MPTP induced neurotoxicity is of concern. It is not at all clear that free radicals are involved in the toxicity of MPTP and MPTP has caused minimal lipid peroxidation. The evidence for endogenous dopamine and exogenous levodopa toxicity is equivocal. The role of neuromelanin is indefinite, some pigmented brainstem nuclei are not sensitive to MPTP and some animals (cat and mouse) who do not have neuromelanin have shown evidence of neurotoxicity with MPTP. Despite all of the interest in toxins and Parkinson's disease, no clear environmental toxin has yet been implicated. Vitamin $\mathrm{E}$ has been proposed as preventive therapy for parkinsonism despite a lack of basal ganglia pathological changes being shown with Vitamin E deficiency and the fact that no definite studies using Vitamin $\mathrm{E}$ as preventive therapy have yet been published.

Despite this inconclusive data the possibility of retarding the progression of Parkinson's disease is real and exciting and must be pursued. The agents being considered are safe, and careful clinical trials must be done to evaluate the therapeutic benefit of augmenting the free radical scavenging system with antioxidants and retarding catecholamine oxidation by inhibiting monoamine oxidase B activity.

\section{REFERENCES}

1. Shaw KM, Lees AJ, Stern GM. The impact of treatment with levodopa on Parkinson's disease. Q J Med 1983;49(195): 283-293.

2. Melamed E. Initiation of levodopa therapy in Parkinsonian patients should be delayed until the advanced stages of the disease. Arch Neurol 1986; 43: 402-405.

3. Ballard PA, Tetrud JW, Langston JW. Permanent human parkinsonism due to 1-methyl-4-phenyl-1,2.3,6-tetrahydropyridine (MPTP): Seven cases. Neurology 1985: 35: 949-956.

4. Snyder SH, D'Amato RJ. MPTP: A neurotoxin relevant to the pathophysiology of Parkinson's disease. Neurology 1986; 36: 250-258.

5. Burns RS, LeWitt PA, Ebert MH, et al. The clinical syndrome of striatal dopamine deficiency. Parkinsonism induced by 1-Methyl-4-phenyl-1,2,3,6-tetrahydropyridine (MPTP). N Engl J Med 1985: 312(22): 1418-1421.

6. Davis GC, Williams AC, Markey SP, et al. Chronic parkinsonism secondary to intravenous injection of meperidine analogues. Psychiatric Res. 1979; 1: 249-254.
7. Barbeau A. Etiology of Parkinson's disease: A research strategy. Can J Neurol Sci 1984; 11: 24-28.

8. Calne DB, Langston JW. Hypothesis. Aetiology of Parkinson's disease. Lancet 1983; 1: 1457-1459.

9. Ambani LM, Van Woert WH, Murphy S. Brain peroxidase and catalase in Parkinson's disease. Arch Neurol 1975: 32: 114-118.

10. Perry TL, Godin DV. Hansen S. Parkinson's disease: A disorder due to nigral glutathione deficiency? Neurosci Lett 1982; 33: 305-310.

11. Graham DG. Catecholamine toxicity: A proposal for the molecular pathogenesis of managanese neurotoxicity and Parkinson's disease. Neurotoxicology 1984; 1: 83-96.

12. Kopin IJ, Markey SP, Burns JN, et al. Mechanisms of neurotoxicity of MPTP. In: Fahn S, ed. Recent Developments in Parkinson's Disease Raven Press, N.Y. 1986; 169-173.

13. Baron JA. Cigarette smoking and Parkinson's disease. Neurology 1986; 36: 1490-1496.

14. Einarson L. Deposits of fluorescent acid-fast products in the nervous system and skeletal muscles of adult rats with chronic Vitamin-E deficiency. J Neurol Neurosurg Psychiat 1953; 16: 98-109.

15. Nelson JS, Fitch CD, Fischer VW, et al. Progressive neuropathologic lesions in Vitamin E-deficient rhesus monkeys. J of Neuropathol Exp Neurol 1981; 40(2): 166-186.

16. Noda Y, McGeer PL, McGeer EG. Lipid peroxides in brain during aging and Vitamin E deficiency: Possible relations to changes in neurotransmitter indices. Neurobiol Aging 1982; 3: 173-178.

17. Perry TL, Yong VW, Clavier RM, et al. Partial protection from the dopaminergic neurotoxin $\mathrm{N}$-methyl-4-phenyl-1,2,3,6-tetrahydropyridine by four different antioxidants in the mouse. Neurosci Lett 1985; 60: 109-114.

18. Baldessarini RJ, Kula NS, Francoeur D, et al. Antioxidants fail to inhibit depletion of striatal dopamine by MPTP. Neurology 1986; 36: 735 .

19. Chiba K, Trevor A, Jr. Castagnoli N. Metabolism of the neurotoxic tertiary amine, MPTP, by brain monoamine oxidase. Biochem Biophys Res Commun 1984; 120(2): 574-578.

20. Cohen G. The pathobiology of Parkinson's disease: Biochemical aspects of dopamine neuron senescence. J Neural Trans, 1983; Suppl 19: 89-103.

21. Slivka A, Cohen G. Hydroxyl radical attack on dopamine. J Biol Chem 1985; 260(29): 15466-15472.

22. Robinson DS. Changes in monoamine oxidase and monoamines with human development and aging. Fed Proc 1975; 34: 103-107.

23. Birkmayer W, Knoll J. Riederer P, et al. Increased life expectancy resulting from addition of $\mathrm{L}$-deprenyl to madopar treatment in Parkinson's disease: A longterm study. J Neural Trans 1985; 65: 113-127.

24. Calne DB, Duvoisin RC, McGeer E. Speculations on the etiology of Parkinson's disease. Adv Neurol 1984; 40; 353-360.

25. Kappus H. Lipid peroxidation: Mechanisms, analysis, enzymology and biological relevance. $I n$. Sies $\mathrm{H}$, ed. 1985 Oxidative Stress, Academic Press, London, 273-310.

26. Cohen G. Oxidative Stress in the nervous system. In: Sies H, ed. 1985 Oxidative Stress, Academic Press, London, 383-402.

27. Heikkila RE, Cohen G. Inhibition of biogenic amine uptake by hydrogen peroxide: A mechamism for toxic effects of 6-hydroxydopamine. Science 1971: 172: 1257-1258.

28. Poirier J, Donaldson J, Barbeau A. The specific vulnerability of substantia nigra to MPTP is related to the presence of transition metals. Biochem Biophys Res Commun 1985; 128(1): 25-33.

29. Drayer B, Burger P, Darwin R, et al. Magnetic resonance imaging of brain iron. AJNR 1986; $7: 373-380$.

30. Smith MT, Sandy MS. Di Monte D. Free radicals, lipid peroxidation, and Parkinson's disease. Lancet 1987; 1: 38.

31. Yong VW, Perry TL, Krisman AA. Depletion of glutathione in brainstem of mice caused by $\mathrm{N}$-methyl-4-phenyl-1,2,3,6-tetrahydropyridine is prevented by antioxidant pretreatment. Neurosci Lett 1986; 63: 56-60.

32. Sershen H, Reith MEA, Hashim A, et al. Protection against 1-methyl-4-phenyl-1,2,3,6-tetrahydropyridine neurotoxicity by the antioxidant ascorbic acid. Neuropharmacology 1985:24(12): 1257-1259.

33. Wagner GC, Jarvis MF, Carelli RM. Ascorbic acid reduces the 
dopamine depletion induced by MPTP. Neuropharmcology 1985; 24(12): 1261-1262.

34. Langston JW, Irwin I. MPTP: Current concepts and controversies. Clin Neuropharmacology 1986; 9(6): 485-507.

35. Sahakian BJ, Carlson KR, DeGirolami U, et al. Functional and structural consequences of longterm dietary L-Dopa treatment in mice. Commun Psychopharmacol 1980: 4: 169-176.

36. Hefti F, Melamed E, Bhawan J, et al. Long-term administration of L-Dopa does not damage dopaminergic neurons in the mouse. Neurology 1981; 31: 1194-1195.

37. Quinn N, Parkes D, Janota I, et al. Preservation of substantia nigra and locus coeruleus in a patient receiving levodopa $(2 \mathrm{~kg})$ plus decarboxylase inhibitor over a four-year period. Movement Disorders 1986; I(1): 65-68.

38. Seiden LS, Vosmer G. Formation of 6-hydroxydopamine in caudate nucleus of the rat brain after a single large dose of methylamphetamine. Pharmacol Biochem Behav 1984:21:29-31.

39. D'Amato RJ, Lipman ZP, Snyder SH. Selectivity of the Parkinsonian neurotoxin MPTP: Toxic metabolite MPP + binds to Neuromelanin. Science 1986: 231: 987-989.

40. Thaw HH, Collins VP, Brunk UT. Influence of oxygen tension, pro-oxidant and antioxidants on the formation of lipid peroxidation products (lipofuscin) in individual cultivated human glial cells. Mech Aging Develop 1984: 24: 211-223.

41. Bannon MJ, Goedert M. Williams B. The possible relation of glutathione, melanin and 1-methyl-4-phenyl-1.2.5.6-tetrahydropyridine (MPTP) to Parkinson's disease. Biochem Pharm 1984: 33(17): 2697-2698

42. Hornykiewicz O. Brain neurotransmitter changes in Parkinson's disease. In: Marsden CD. Fahn S, eds. Movement Disorders, Vol 1. Butterworth, Boston, 41-58.

43. McGeer PL, McGeer EG, Suzuki JS. Aging and extrapyramidal function. Arch Neurol 1977:34: 33-35.

44. Spencer P, Calne DB, McGeer E, et al. Alzheimer's disease, Parkinson's disease, and motoneurone disease: Abiotropic interaction between ageing and environment? Lancet 1986:2: 1067-1070.

45. Rajput AH, Uitti RJ, Laverty W, et al. Early onset Parkinson's disease in Saskatchewan - Environmental considerations for etiology. Can J Neurol Sci 1986: 13: 312-316.

46. Jarvis MF, Wagner GC. Age-dependent effects of 1-methyl-4phenyl-1,2,5,6-tetrahydropyridine (MPTP). Neuropharmacology 1985; 24(6): $581-583$.

47. Forno LS, Langston JW. DeLanney LE, et al. Locus ceruleus lesions and eosinophilic inclusions in MPTP-treated monkeys. Ann Neurol 1986; 20: 449-455.

48. Ramsden DB, Williams AC. Production in nature of compound resembling methylphenyltetrahydropyridine, A possible cause of Parkinson's disease. Lancet 1985; 1: 215.

49. Fellman JH, Nutt JN. MPTP-like molecules and Parkinson's disease. Lancet 1985; 1: 924.
50. Testa B, Naylor R, Costall B, et al. Does an endogenous methyIpyridinium analogue cause Parkinson's disease? J Pharm Pharmacol 1985: 37: 679-680.

51. Barbeau A, Roy M, Paris S, et al. Ecogenetics of Parkinson's disease: 4-hydroxylation of debrisoquine. Lancet 1985: 2: 1213-1216.

52. Spencer PS. Nunn PB. Hugon J, et al. Motorneurone Disease on Guam: Possible role of a food neurotoxin. Lancet 1986: 1: 965 .

53. Mandell HG, Cohn VH. Fat soluble vitamins. In: Goodman \& Gilman's The Pharmacological Basis of Therapeutics. 7th Edition. Macmillian, N.Y. 1985: 1573-1591.

54. McCay PB, King MM. Vitamin E: Its role as a biological free radical scavenger and its relationship to the microsomal mixedfunction oxidase system. In: Vitamin E: A Comprehensive Treatise. Machlin LJ. ed. Dekker, N.Y. 1980: 289-317.

55. Quintanilha AT, Packer L. Davies JMS, et al. Membrane effects of Vitamin E deficiency: Bioenergetic and surface charge density studies of skeletal muscle and liver mitochondria. In: Vitamin $E$ : Biochemical, Hematological, and Clinical Aspects, Lubin B, Machlin LJ, eds. Annals N.Y. Acad Sci 1982: 393: 32-47.

56. Diplock AT. The role of Vitamin $\mathrm{E}$ in biological membranes. $\mathrm{l}$ : Biology of Vitamin E (Ciba Foundation Symposium 101). Pitman. London 1983: 45-55.

57. Satya-Murti S. Howard L. Krohel G. et al. The spectrum of neurologic disorder from Vitamin E deficiency. Neurology 1986: 36: 917-921.

58. Muller DPR, Lloyd JK. Wolff OH. Vitamin E and Neurological Function. Lancet 1983: 1: 225-228.

59. Brin MF, Pedley TA, Lovelace RE. et al. Electrophysiologic features of abetalipoproteinemia: Functional consequences of vitamin E deficiency. Neurology 1986: 36: 669-673.

60. Riederer P, Youdim MB. Monoamine oxidase activity and monoamine metabolism in brains of Parkinsonian treated 1-Deprenyl. J Neurochem 1986: 46(5): 1359-1365.

61. Cohen G, Pasik P. Cohen B, et al. Pargyline and deprenyl prevent the neurotoxicity of 1-methyl-4-phenyl-1.2,3.6-tetrahydropyridine (MPTP) in monkeys. Eur J Pharmacol 1985: 106: 209-210.

62. Willson RL. Free radical protection: why vitamine E. not vitamin C, B-carotene or glutathione? In: Biology of Vitamin E. (Ciba Foundation Symposium 101). Pitman. London, 1983: 19-44.

63. Elsworth JD, Glover V. Reynolds GP. et al. Deprenyl administration in man: a selective monoamine oxidase B inhibitor without the 'cheese effect'. Psychopharmacology 1978: 57: 33-38.

64. Yahr MD, Mendoza MR, Moros D. et al. Treatment of Parkinson`s disease in early and late phases. Use of pharmacological agents with special reference to deprenyl (selegiline). Acta Neurol Scand 1983; 95: 95-102. 